\title{
Inhibitory Effect of Acyl-CoA: Cholesterol Acyltransferase Inhibitor-Low Density Lipoprotein Complex on Experimental Atherosclerosis
}

\author{
Yoshihiko TAUChI, ${ }^{*, a}$ Akihisa Yoshimi, ${ }^{b}$ Hiroaki ShIRAhase, ${ }^{b}$ Juichi Sato, ${ }^{a}$ Keiji Ito, ${ }^{a}$ and \\ Kazuhiro Morimoto ${ }^{a}$ \\ ${ }^{a}$ Department of Pharmaceutics, Hokkaido College of Pharmacy; 7-1 Katsuraoka-cho, Otaru 047-0264, Japan: and \\ ${ }^{b}$ Research Laboratories, Kyoto Pharmaceutical Industries, Ltd.; 38, Nishinokyo Tsukinowa-cho Nakakyo-ku, Kyoto \\ 604-8444, Japan. Received July 15, 2002; accepted September 27, 2002
}

\begin{abstract}
KV-2920 is a novel acyl-CoA: cholesterol acyltransferase (ACAT) inhibitor. To confirm the efficacy of KV2920-low density lipoprotein (LDL) complex (KV-LDL complex) as a drug-carrier complex on experimental atherosclerosis, we examined its inhibitory effects in vitro and in vivo. LDL was isolated from human plasma and the KV-LDL complex was prepared by incubation in the presence of Celite 545 . The complex contained about $800 \mathrm{~mol} \mathrm{KV-2920}$ in $1 \mathrm{~mol}$ LDL. The cholesterol levels in the serum and aorta of atherogenic mice after 14 weeks of feeding were significantly higher than those of nonatherogenic mice. With the intravenous injection of KV-LDL complex, although the cholesterol levels in the serum were not influenced, the level of cholesterol ester in the aorta of atherogenic mice was significantly reduced. The concentration of cholesterol ester in the macrophages derived from ICR mice was predominantly increased by incubation with LDL for $48 \mathrm{~h}$, this increase was significantly inhibited by incubation with KV-LDL complex. Moreover, the complex also inhibited the increase of cholesterol ester in macrophages following incubation with oxidized LDL. These findings suggest that KV-LDL complex inhibits the foam cell formation of macrophages though action of KV-2920 as an ACAT inhibitor, and prevents the accumulation of cholesterol ester in the aorta of atherogenic mice. Therefore, KV-LDL complex may be useful as a drug-carrier complex in antiatherosclerotic therapy.
\end{abstract}

Key words drug low density lipoprotein (LDL) complex; drug delivery; antiatherosclerosis; acyl-CoA: cholesterol acyltransferase (ACAT) inhibitor

In an early stage of the progression of atherosclerosis, atherosclerotic plaques develop due to the accumulation of foam cells derived from macrophages or fibroblasts. ${ }^{1)}$ Many studies have shown that low density lipoprotein (LDL) penetrates the epithelium of blood cells where it is modified, then incorporated in macrophages by a scavenger receptor. ${ }^{2,3)}$ Since modified LDL and macrophages play an important role in foam cell formation at atherosclerosis lesions, preventing the conversion of macrophages to foam cells by incorporation of modified LDL or removing accumulated cholesterol ester (CE) in foam cells is likely to have an antiatherosclerotic effect.

Acyl-CoA: cholesterol acyltransferase (ACAT) is a major enzyme associated with $\mathrm{CE}$ accumulation in foam cells derived from macrophages during atherosclerotic plaque formation. ${ }^{4)}$ Therefore, an ACAT inhibitor would be a promising drug for preventing foam cell formation. In fact, many studies have reported that an ACAT inhibitor prevents foam cell formation by macrophages and the development of atherosclerotic plaques. ${ }^{5-7)}$ However, most ACAT inhibitors have problems associated with low oral bioavailability and adrenal and/or hepatic toxicity. ${ }^{8,9)}$ In particular, adrenotoxicity is a major problem if an ACAT inhibitor is to be used in clinical situations. Therefore, use of such an inhibitor in antiatherosclerotic therapy makes selective and efficient delivery of the drug to the atherogenic lesions in the aorta very important. We have demonstrated that dexamethasone palmitate (DP)-LDL complex inhibits foam cell formation of macrophages in a series of in vitro experiments, and prevents $\mathrm{CE}$ accumulation in the aorta of atherogenic mice. ${ }^{10-12)}$ In addition, the complex predominantly accumulates in early atherogenic lesions of the aorta of these mice after intravenous injection. ${ }^{12}$ LDL is thus a suitable carrier for drug delivery into early atherogenic lesions.

KV-2920 (N-(1-decyl-4,6-dimethylindolin-7-yl)-2,2-dimethylpropanamide) has been synthesized as one member of a series of $N$-(4,6-dimethylindolin-7-yl) amides. ${ }^{13)} \mathrm{KV}-2920$ is a potent ACAT inhibitor and antioxidant although it has a very high lipophilicity. ${ }^{13)}$ Since it is necessary, however, that any drug to be incorporated into LDL be highly lipophilic, ${ }^{14)}$ this appears to make it appropriate for use in a drug-LDL complex to treat atherosclerosis.

In the present study, we examined whether the KV-2920LDL complex (KV-LDL complex) was able to prevent $\mathrm{CE}$ accumulation in the aorta of an experimental mouse model of atherosclerosis. The inhibitory effect of the complex on foam cell formation of macrophages following incubation with LDL was also determined.

\section{MATERIALS AND METHODS}

The investigation conformed to the Guiding Principles for the Care and Use of Experimental Animals in the Hokkaido College of Pharmacy (published in 1988). All procedures involving human subjects were conducted in accordance with the Declaration of Helsinki and informed consent was obtained from all volunteers.

Animals Male ICR mice were obtained from Japan SLC, Inc. (Hamamatsu, Japan) and were used for experiments at 6 weeks of age.

Materials KV-2920 and KV-2919 (internal standard for HPLC) were synthesized in the research laboratories of Kyoto Pharmaceutical Industries, Ltd. (Kyoto, Japan) as test compounds. The solubility of KV-2920 in $1 / 15 \mathrm{M}$ phosphate buffer ( $\mathrm{pH}$ 6.5) is $0.04 \mu \mathrm{g} / \mathrm{ml}$. Celite 545 was obtained from Kanto Chemical Co. Inc. (Tokyo, Japan). Cholesterol es- 
terase, cholesterol oxidase and peroxidase were purchased from Toyobo Co. (Tokyo). All other chemicals were of analytical grade.

LDL Isolation The LDL $(d=1.019-1.063 \mathrm{~g} / \mathrm{ml})$ fraction was isolated by a sequential ultra-centrifugation $(100000 \times \boldsymbol{g})$ from plasma of healthy volunteers, and then dialyzed against phosphate-buffered saline (PBS, pH 7.4) at $\left.4{ }^{\circ} \mathrm{C} .{ }^{15}\right)$ This LDL fraction was concentrated to $100 \mathrm{mg}$ protein/100 ml using a Centriprep 30 (Millipore Co., Bedford, MA, U.S.A.), filtered through a MILLEX-HV filter $(0.45 \mu \mathrm{m}$, Millipore), and then stored at $4{ }^{\circ} \mathrm{C}$ in the dark until required $(<1$ week). Oxidized LDL was prepared by incubation with $5 \mu \mathrm{M} \mathrm{CuSO}$ for $20 \mathrm{~h}$ at $37^{\circ} \mathrm{C}$.

Preparation of KV-LDL Complex The KV-LDL complex was prepared using Celite 545 as described previously. ${ }^{10)}$ Briefly, Celite 545 (100 mg) and $1 \mathrm{ml} \mathrm{KV-2920} \mathrm{solu-}$ tion $(1 \mathrm{mg} / \mathrm{ml}$ in $\mathrm{MeOH})$ were vortex mixed. The mixture was evaporated under vacuum for $30 \mathrm{~min}$ and then the residue was thoroughly pulverized. The residue and $2 \mathrm{ml}$ LDL suspension (300-400 $\mu \mathrm{g}$ protein $/ \mathrm{ml})$ were mixed gently, compacted under $\mathrm{N}_{2}$ and then incubated for $20 \mathrm{~h}$ with shaking at $37^{\circ} \mathrm{C}$. After incubation, the supernatant of this mixture was dialyzed against PBS, and concentrated to $100 \mathrm{mg}$ protein $/ 100 \mathrm{ml}$ using a Centriprep 30. This suspension was filtered though a Millex-HV filter and used for experiments as the KV-LDL complex.

Determination of Drug Concentration The KV-2920 concentration in the KV-LDL complex was measured by HPLC as follows: a mixture of the complex (50 $\mu \mathrm{l}), \mathrm{KV}-2919$ (as an internal standard, $50 \mu \mathrm{l}$ ), and $0.1 \mathrm{M} \mathrm{NaOH}$ solution $(800 \mu \mathrm{l})$ was extracted with ethyl acetate $(4 \mathrm{ml})$. Part of the organic phase $(3 \mathrm{ml})$ was evaporated under vacuum at $30^{\circ} \mathrm{C}$. The residue was dissolved in $120 \mu \mathrm{l} \mathrm{MeOH} / \mathrm{H}_{2} \mathrm{O}(85: 15)$, and a $50 \mu \mathrm{l}$ aliqot was subjected to HPLC using a system (Shimadzu Co., Kyoto) involving a 5- $\mu \mathrm{m}$ Mightysil RP-18 GP column $(4.6 \times 150 \mathrm{~mm}$, Cica-Merck, Kanto Chemical). The mobile phase was $\mathrm{MeOH} / \mathrm{H}_{2} \mathrm{O}(85: 15)$ and flow rate was $1.5 \mathrm{ml} / \mathrm{min}$. The eluate was monitored at $254 \mathrm{~nm}$ and quantified using a model C-R6A chromatopac integrator (Shimadzu). The concentrations were determined with respect to a standard curve of KV-2920.

Preparation of Macrophages Peritoneal cells from unstimulated ICR mice were washed twice with PBS by centrifugation and were suspended at $1 \times 10^{6}$ cells $/ \mathrm{ml}$ in serumfree medium (SFM) (Gibco BRL, Life Technologies, Rockville, MD, U.S.A.) supplemented with $50 \mu \mathrm{M}$ 2-mercaptethanol and $10 \mu \mathrm{g} / \mathrm{ml}$ gentamycin. The cells were seeded in 24-well culture plates (Becton Dickinson, Lincoln Park, NJ, U.S.A.) containing $1.0 \mathrm{ml}$ cell suspension per well and incubated for $90 \mathrm{~min}$ at $37^{\circ} \mathrm{C}$ in a $\mathrm{CO}_{2}$ incubator. After incubation, nonadherent cells were removed by three washes with SFM and the macrophage monolayers were placed in fresh SFM for $20 \mathrm{~h}$ at $37^{\circ} \mathrm{C}$ in a $\mathrm{CO}_{2}$ incubator.

Assay of Cholesterol Accumulation in Macrophages The cholesterol accumulation in macrophages was assayed as previously described. ${ }^{10)}$ LDL and/or complex was added to wells of macrophage monolayers and incubated for the indicated periods at $37^{\circ} \mathrm{C}$ in a $\mathrm{CO}_{2}$ incubator. After incubation, the monolayers were washed twice with SFM and PBS, respectively. Lipids and proteins were subsequently extracted directly from the monolayers with a hexane/isopropanol
(3:2) mixture and $0.1 \mathrm{~mol} / 1 \mathrm{NaOH}$ solution, respectively. These extracts were used to determine the cellular concentration of cholesterols and protein.

Measurement of Cellular Cholesterols Cellular cholesterol was measured by a fluorometric enzymatic method. ${ }^{10)}$ Briefly, $200 \mu \mathrm{l}$ cellular lipid extract was evaporated with $2.5 \mathrm{mg}$ Triton X-100. This residue was combined with $200 \mu \mathrm{l}$ of an enzyme mixture and incubated for $30 \mathrm{~min}$ at $37^{\circ} \mathrm{C}$. Following incubation, $0.1 \mathrm{~mol} / 1 \mathrm{NaOH}(2.8 \mathrm{ml})$ was added to stop the reaction, and the fluorescence intensity was measured at an excitation wavelength of $323 \mathrm{~nm}$ and an emission wavelength of $420 \mathrm{~nm}$ using a spectro-fluorophotometer (Model FP-770, JASCO, Tokyo). The enzyme mixture for free cholesterol (FC) contained $0.12 \mathrm{U} / \mathrm{ml}$ cholesterol oxidase, $45 \mathrm{U} / \mathrm{ml}$ peroxidase, $0.5 \mathrm{mg} / \mathrm{ml}$ homovanillic acid (Wako Pure Chemical Industries, Ltd., Osaka, Japan) and $2 \mathrm{mg} / \mathrm{ml}$ Triton $\mathrm{X}-100$ in $100 \mathrm{mmol} / 1$ sodium phosphate buffer ( $\mathrm{pH}$ 7.0). The enzyme mixture for total cholesterol (TC) contained $0.36 \mathrm{U} / \mathrm{ml}$ cholesterol esterase in the enzyme mixture for FC. Cellular $\mathrm{CE}$ was determined by subtracting FC from TC.

Preparation of Atherogenic Mice Nonatherogenic and atherogenic mice were maintained with ICR mice. ${ }^{16)}$ Among the nonatherogenic animals, ICR mice were fed a normal diet containing $10 \%$ coconut oil (linoleic acid content: below $1 \%$ ), $0.8 \%$ vitamin mixture, $4 \%$ salt mixture, $2 \%$ agar, $20 \%$ casein, and $63.2 \%$ sucrose. Among atherogenic animals, ICR mice were fed an atherogenic diet consisting of the normal diet plus $10 \%$ linoleic acid, $1.5 \%$ cholesterol, $0.5 \%$ cholic acid, and $51.2 \%$ sucrose. Each mouse was given $6 \mathrm{~g}$ of the appropriate diet daily for 14 weeks. Although formation of gallstones and a fatty liver were observed in all atherogenic mice, no animal died in any group during the experiment.

$\mathrm{KV}$-LDL complex was administered to the mice as follows: the complex was diluted with PBS to the concentrations indicated in the Results, and then the solution was filtered through a MILLEX-HV filter just before administration. The solution of KV-LDL complex $(100 \mu \mathrm{l})$ was injected via the tail vein every week from 8 to 14 weeks ( 7 times).

Measurement of Cholesterol Levels in Serum and Aorta At the end of the experiment (14th week), samples of serum and aorta were obtained from the mice. A sample was obtained on the day following the final injection and an artery from the heart to the diaphragm was taken as the aorta. TC and FC concentrations in the serum were determined using commercial kits (Wako Pure Chemical). The aorta was freeze-dried and its dry weight measured. Subsequently, the aorta was extracted with a $2 \mathrm{ml} \mathrm{CHCl}_{3} / \mathrm{MeOH}(2: 1)$ mixture for $20 \mathrm{~min}$ at $50^{\circ} \mathrm{C}$. The extract was evaporated under vacuum and the residue then was dissolved in $500 \mu \mathrm{lEtOH}$. The $\mathrm{TC}$ and FC concentrations in this suspension were measured in the same way as cellular cholesterol.

Other Determination Protein was measured using Coomassie Protein Assay Reagents (Pierce Chemical Company, Rockford, IL, U.S.A. $)^{17)}$ using bovine serum albumin as a standard. TC, FC, and triglyceride (TG) concentrations in LDL and the KV-LDL complex were measured using commercial kits (Wako Pure Chemical).

Statistical Analysis Statistical analysis was performed using Fisher's Protected Least Significant Difference (PLSD) 
test, which is a post-hoc test from a statistical software package (Statview; Abacus Concepts Inc., Berkeley, CA, U.S.A.). A $p$ value of 0.05 or less was considered a significant difference between the sets of data.

\section{RESULTS}

Characteristics of LDL and KV-LDL Complex The characteristics of the LDL and KV-LDL complex are summarized in Table 1. The lipid (TC, FC, and TG) and protein concentrations of $\mathrm{KV}$-LDL complex were similar to the corresponding concentrations of LDL. The KV-2920 concentration was $615.2 \mu \mathrm{g} / \mathrm{ml}$, and the amount of KV-2920 contained in the KV-LDL complex was $800 \pm 40 \mathrm{~mol} / \mathrm{mol} \mathrm{LDL} \mathrm{(LDL}$ molecular weight of $5.5 \times 10^{5}$ based on the protein concentration). The electrophoresis pattern of the KV-LDL complex was the same as that of LDL (data not shown). Furthermore, neither aggregation of the complex nor a reduction in $\mathrm{KV}$ 2920 concentration in the complex was seen after 4 weeks storage at $4{ }^{\circ} \mathrm{C}$.

Effect of KV-LDL Complex on Cholesterol Levels in Serum and Aorta of Atherogenic Mice Table 2 shows the

Table 1. Characteristics of KV-LDL Complex

\begin{tabular}{lcc}
\hline \hline & KV-LDL complex & LDL \\
\hline Total cholesterol $(\mathrm{mg} / 100 \mathrm{ml})$ & $290.0 \pm 15.0$ & $304.5 \pm 5.6$ \\
Free cholesterol $(\mathrm{mg} / 100 \mathrm{ml})$ & $81.7 \pm 1.9$ & $84.6 \pm 1.0$ \\
Triglyceride $(\mathrm{mg} / 100 \mathrm{ml})$ & $55.8 \pm 2.3$ & $54.5 \pm 0.1$ \\
Protein $(\mathrm{mg} / 100 \mathrm{ml})$ & $99.9 \pm 3.8$ & $99.8 \pm 0.7$ \\
KV-2920 concentration $(\mu \mathrm{g} / \mathrm{ml})$ & $615.2 \pm 21.1$ & - \\
\hline
\end{tabular}

Values are mean \pm S.D. $(n=5)$.

Table 2. Effect of KV-LDL Complex on Cholesterol Concentration in Serum of Atherogenic Mice

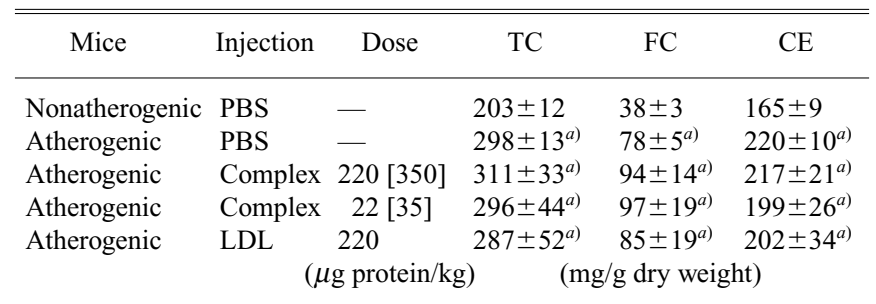

Each value is the mean \pm S.D. $(n=8)$. TC, total cholesterol. FC, free cholesterol. CE, cholesterol ester. Complex, KV-LDL complex. LDL, native LDL. [ ], injected dose as $\mathrm{KV}-2920$ (nmol/kg). KV-LDL complex and native LDL were intravenously injected to mice at the indicated dose, respectively, once a week from 8 to 14 weeks. The serum was obtained from mice on the day following the final injection, and cholesterol concentrations in the serum were measured. a) $p<0.05$, compared with the nonatherogenic mice. concentration of TC, FC, and $\mathrm{CE}$ in the serum of nonatherogenic and atherogenic mice at the end of the experiment. Their levels in atherogenic mice treated with PBS were significantly higher than those in nonatherogenic mice treated with PBS. The increase in cholesterol levels in the serum of atherogenic mice showed that hyperlipidemia or hypercholesterolemia had been induced, although there was no effect on cholesterol levels in the serum following injection of $\mathrm{KV}-\mathrm{LDL}$ complex or LDL into atherogenic mice.

As shown in Table 3, the levels of TC, FC, and CE in the aorta of atherogenic mice treated with PBS were significantly higher than those of treated nonatherogenic. In particular, the CE level in the aorta of atherogenic mice was 2.9-fold higher than that of nonatherogenic mice. This increased CE indicated the induction of atherosclerotic plaque-like $\mathrm{CE}$ accumulation in the aorta of these mice. Either KV-LDL complex or native LDL was administered intravenously to atherogenic mice from 8 to 14 weeks. The levels of TC, FC, and $\mathrm{CE}$ in the aorta of atherogenic mice treated with both high (220 $\mu \mathrm{g}$ protein $/ \mathrm{kg}, 350 \mathrm{nmol} \mathrm{KV}-2920 / \mathrm{kg})$ and low $(22 \mu \mathrm{g}$

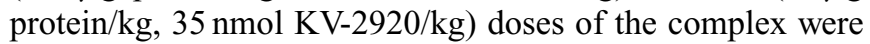
significantly lower than those of atherogenic mice treated with PBS. On the other hand, cholesterol levels in the aorta of atherogenic mice were unchanged following treatment with LDL.

Inhibitory Effect of KV-LDL Complex on Foam Cell Formation The inhibitory effect of KV-LDL complex on foam cell formation of macrophages induced by incubation with LDL was examined. LDL $(100 \mu \mathrm{g}$ protein/well) and KV-LDL complex $(20,10,5$, and $1 \mu \mathrm{g}$ protein/well, respectively) were added to macrophages and then the macrophages were incubated for $48 \mathrm{~h}$. TC, FC, and CE concentrations in the macrophages incubated with LDL alone were significantly increased compared with those in macrophages incubated with medium only (350 vs. $109 \mu \mathrm{g} / \mathrm{mg}$ cell protein, 213 vs. $99 \mu \mathrm{g} / \mathrm{mg}$ cell protein, $137 v s .9 \mu \mathrm{g} / \mathrm{mg}$ cell protein, respectively) (Fig. 1). In particular, the CE concentration of macrophages incubated with LDL increased more than 13fold compared with that of normal macrophages (Fig. 1, lower). This increased cellular CE concentration indicated the induction of foam cell formation of macrophages. After addition of KV-LDL complex, the increase in CE concentration in macrophages following incubation with LDL was significantly inhibited, to a degree that depended on the amount of the complex addition (Fig. 1, lower). In contrast, the only inhibitory effect of KV-LDL complex on the increase in FC concentration in macrophages following incubation with LDL was seen at $20 \mu \mathrm{g} /$ well.

Table 3. Effect of KV-LDL Complex on Cholesterol Concentration in Aorta of Atherogenic Mice

\begin{tabular}{|c|c|c|c|c|c|}
\hline Mice & Injection & Dose & $\mathrm{TC}$ & $\mathrm{FC}$ & $\mathrm{CE}$ \\
\hline Nonatherogenic & PBS & - & $5.83 \pm 0.12$ & $5.41 \pm 0.16$ & $0.42 \pm 0.06$ \\
\hline Atherogenic & PBS & - & $7.61 \pm 0.28^{a)}$ & $6.41 \pm 0.29^{a)}$ & $1.20 \pm 0.10^{a)}$ \\
\hline Atherogenic & Complex & $220[350]$ & $6.42 \pm 0.13^{a, b)}$ & $5.67 \pm 0.10^{a, b)}$ & $0.75 \pm 0.05^{a, b)}$ \\
\hline Atherogenic & Complex & $22[35]$ & $6.50 \pm 0.26^{a, b)}$ & $5.89 \pm 0.23^{a, b)}$ & $0.61 \pm 0.08^{a, b)}$ \\
\hline Atherogenic & LDL & $\begin{array}{l}220 \\
(\mu \mathrm{g} \text { protein } / \mathrm{kg})\end{array}$ & $7.34 \pm 0.76^{a)}$ & $\begin{array}{c}6.16 \pm 0.51^{a)} \\
\text { (mg/g dry weight) }\end{array}$ & $1.18 \pm 0.27^{a)}$ \\
\hline
\end{tabular}

Each value is the mean \pm S.D. $(n=8)$. TC, total cholesterol. FC, free cholesterol. CE, cholesterol ester. Complex, KV-LDL complex. LDL, native LDL. [ ], injected dose as $\mathrm{KV}-2920(\mathrm{nmol} / \mathrm{kg})$. KV-LDL complex and native LDL were intravenously injected to mice with indicated dose, respectively, once a week from 8 to 14 weeks. The aorta was taken from mice on the day following the final injection, and cholesterol concentrations in the aorta were measured. $a$ ) $p<0.05$, compared with the nonatherogenic mice. $b$ ) $p<0.05$, compared with atherogenic mice treated with PBS. 

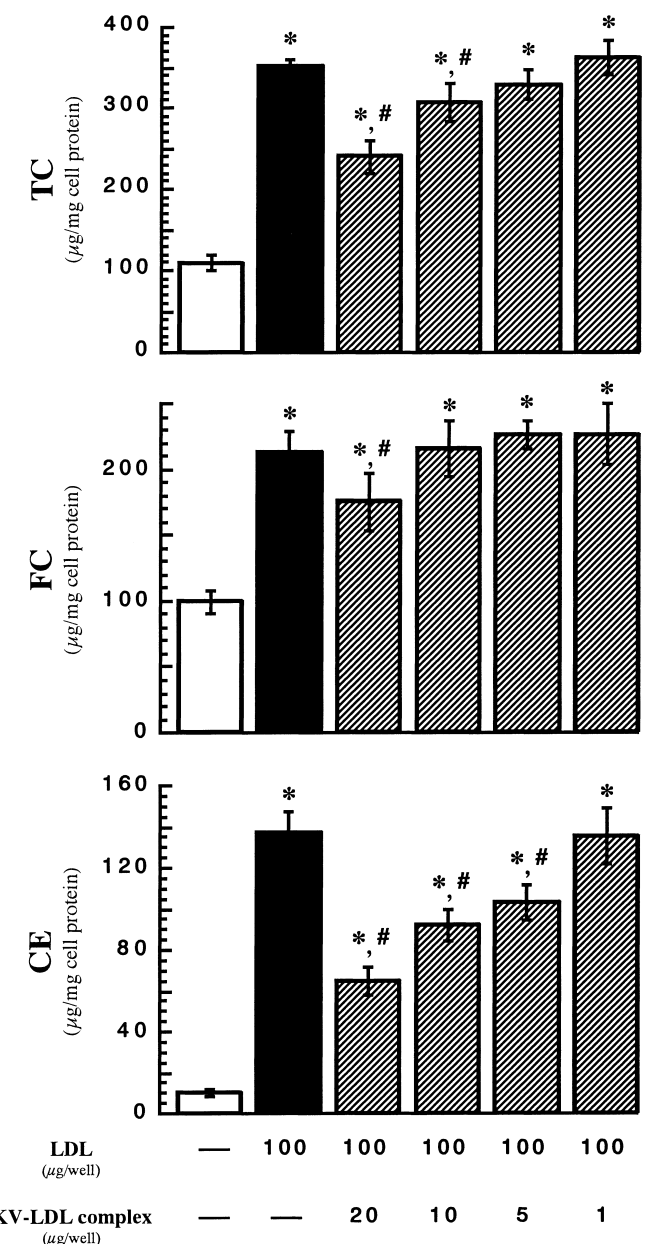

$(\mu \mathrm{g} / \mathrm{well})$

Fig. 1. Inhibitory Effect of KV-LDL Complex on Cholesterol Accumulation in Macrophages Induced by Incubation with LDL

Macrophages were incubated with LDL (100 $\mu \mathrm{g} / \mathrm{well})$ and KV-LDL complex (20, 10,5 , or $1 \mu \mathrm{g} /$ well) for $48 \mathrm{~h}$ at $37^{\circ} \mathrm{C}$. Final KV-2920 concentration in the KV-LDL complex medium was $22.7,11.4,5.7$, or $1.1 \mu \mathrm{M}$. After incubation, lipids and protein were extracted and their levels measured. Data are shown as cellular concentrations ( $\mu \mathrm{g} / \mathrm{mg}$ cell protein) of TC (upper panel), FC (middle panel), and CE (lower panel). Values are expressed as means \pm S.D. of 6 experiments. The amount of LDL or $\mathrm{KV}$-LDL complex is indicated under the column as protein content and indicates the addition of PBS instead of LDL or KV-LDL complex. $* p<0.05$, compared with the macrophages incubated with medium only. $\# p<0.05$, compared with the macrophages incubated with LDL.

Next, we investigated whether KV-LDL complex could prevent the foam cell formation of macrophages induced by oxidized LDL. As shown in Fig. 2, the CE concentration in macrophages was markedly increased by $24 \mathrm{~h}$ incubation with oxidized LDL, indicating the induction of foam cell formation of macrophages. KV-LDL complex (10 and $20 \mu \mathrm{g}$ protein/well) significantly inhibited the increased CE concentration in macrophages when the complex was added to macrophages at the same time as oxidized LDL (Fig. 2, lower). Therefore, it was clear that this complex could inhibit the foam cell formation of macrophages induced by both native and oxidized LDL.

\section{DISCUSSION}

The feasibility of using KV-LDL complex as a drug-carrier complex for a drug delivery system for atherosclerosis was examined in this study in a series of in vitro and in vivo experiments. Because LDL is unstable and easily modified,
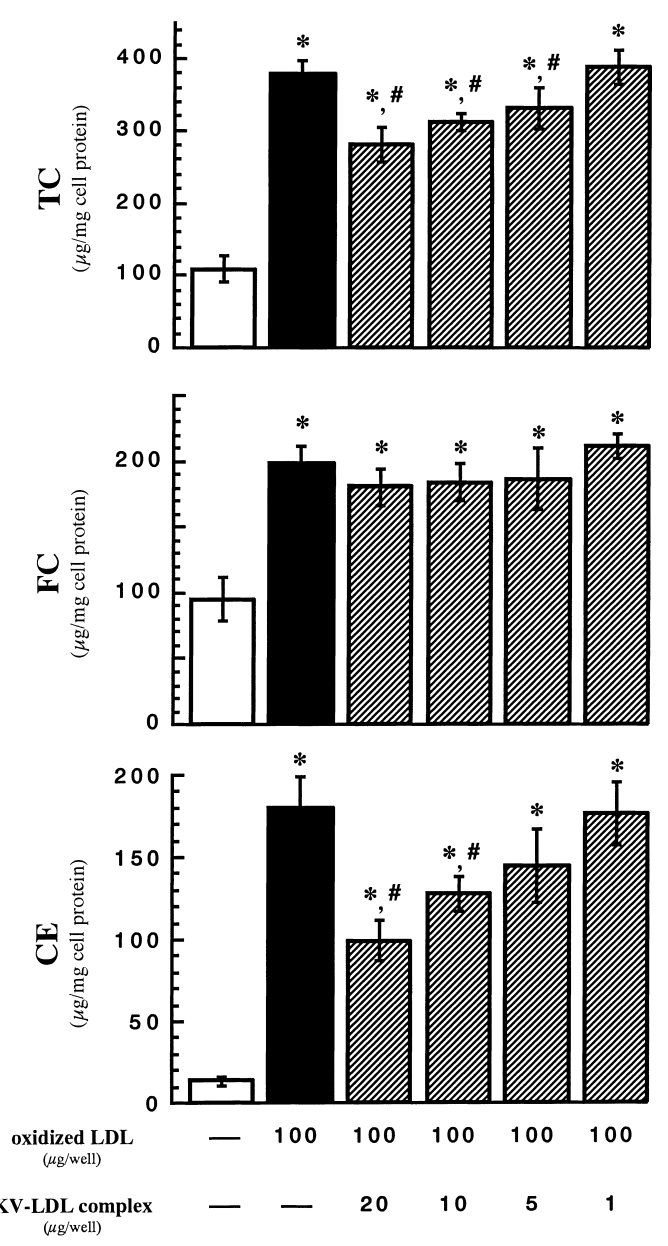

Fig. 2. Inhibitory Effect of KV-LDL Complex on Cholesterol Accumulation in Macrophages Induced by Incubation with Oxidized LDL

Macrophages were incubated with oxidized LDL ( $100 \mu \mathrm{g} /$ well) and KV-LDL complex $(20,10,5$, or $1 \mu \mathrm{g} /$ well $)$ for $48 \mathrm{~h}$ at $37^{\circ} \mathrm{C}$. Final KV-2920 concentration in the $\mathrm{KV}$-LDL complex medium was $22.7,11.4,5.7$, or $1.1 \mu \mathrm{M}$. After incubation, lipids and protein were extracted and their levels measured. Other details are the same as those in Fig. 2. $* p<0.05$, compared with the macrophages incubated with medium only. $\# p<0.05$, compared with the macrophages incubated with oxidized LDL.

prevention of the degradation and modification of LDL during the preparation of $\mathrm{KV}-\mathrm{LDL}$ complex was very important. The physiological characteristics of KV-LDL complex were similar to those of LDL (Table 1), and its electrophoretic mobility was also similar (data not shown). Moreover, no aggregation or degradation of KV-LDL complex took place during cold storage for up to 4 weeks. These findings indicate that KV-LDL complex can be prepared without any degradation or modification of LDL, and used for subsequent in vivo and in vitro experiments.

The serum and aorta cholesterol levels of atherogenic mice were significantly increased compared with those of nonatherogenic mice, suggesting that hyperlipidemia and development of atherosclerotic plaques in the aorta had been induced in the atherogenic mice. The KV-LDL complex significantly inhibited the increase in CE in the aorta of these mice (Table 3) with no change in serum cholesterol levels (Table 2). Lipid-lowering is a major priority for patients with atherosclerosis, because hyper-lipidemia or hyper-cholesterolemia is one of the major risk factors associated with the development of this condition. In animal experiments, lipidlowering has been shown to be a useful way of preventing the 
development of experimental atherosclerosis. For example, Yamaguchi et al. demonstrated that probucol, an antiatherosclerotic drug, prevents the increase in cholesterol in the serum, and consequently inhibits the increase in $\mathrm{CE}$ in the aorta of atherogenic mice which were prepared by the same method that we used. ${ }^{16)}$ However, the KV-LDL complex inhibited only the increase in CE level in the aorta but the increase in cholesterol in the serum of these mice. The injection of KV-LDL complex or native LDL in the long-term had no effect on serum cholesterol, indicating that the cholesterol amount in the KV-LDL complex was negligible compared with the cholesterol in the serum of atherogenic mice. These findings indicate that KV-LDL complex inhibits the development of atherosclerotic plaques in the aorta without any reduction in serum cholesterols.

When macrophages were incubated with native LDL for $48 \mathrm{~h}$, they were converted to foam cells with high levels of CE (Fig. 1). The KV-LDL complex inhibited the foam cell formation of macrophages following incubation with LDL, with the inhibitory effect depending on the amount added (Fig. 1, lower). In a previous study, we demonstrated that the DP-LDL complex could be spontaneously oxidized and incorporated into macrophages in the same way as native LDL, and then inhibited the foam cell formation of macrophages induced by incubation with native LDL. ${ }^{11)}$ We furthermore showed that dexamethasone could inhibit the foam cell formation of macrophages induced by native LDL. ${ }^{11)}$ Similarly, KV-LDL complex was oxidatively modified during a $24 \mathrm{~h}$ incubation with macrophages in this study (data not shown), and it is well known that ACAT inhibitor inhibits foam cell formation by preventing intracellular cholesterol metabolism. ${ }^{18)}$ Therefore, we believe that the KV-LDL complex was modified and incorporated into macrophages in the same way as native LDL, and then the KV-2920 released from the complex inhibited the foam cell formation of macrophages by inhibition of macrophage ACAT activity.

KV-LDL complex also inhibited the foam cell formation of macrophages induced by incubation with oxidized LDL that was modified by $\mathrm{CuSO}_{4}$ (Fig. 2). KV-2920 is a potent antioxidant. ${ }^{13)}$ Antioxidants are believed to be beneficial in atherosclerosis because they prevent oxidative modification of native LDL and so inhibit the foam cell formation of macrophages. Indeed, it has been reported that antioxidants could play a potential role in the prevention of atherosclerosis by inhibiting incorporation of oxidized LDL into macrophages. ${ }^{19)}$ In our experiments, the KV-LDL complex was oxidatively modified during the incubation with macrophages (data not shown) and inhibited the foam cell formation of macrophages induced by oxidized LDL (Fig. 2). We therefore believe that KV-2920 acts as an ACAT inhibitor, not an antioxidant, inhibiting the foam cell formation of macrophages following administration of the KV-LDL complex.

Recent studies have demonstrated that exogenous LDL and modified LDL were selectively incorporated into atherosclerotic lesions in the aorta in an animal model of atherosclerosis. ${ }^{20,21)}$ Native LDL migrates under the epithelium of vascular smooth muscle and is oxidatively modified. The oxidized LDL is incorporated into macrophages via the scavenger receptor pathway, and then the macrophages are converted to foam cells. Consequently, an atherosclerotic plaque consists of an accumulation of foam cells. ${ }^{1,2)}$ The incorporation of modified, mainly oxidized, LDL into macrophages via the scavenger receptor pathway is not restricted by the "feedback regulation", while native LDL incorporation by LDL receptors is regulated. ${ }^{2)}$ Accordingly, drug-LDL complex can deliver a large amount of antiatherosclerotic drug in the macrophages in the subendothelial space of the aorta, and then inhibit the development of atherosclerotic plaques if the drug-LDL complex accumulates in the macrophages in the same way as LDL. In our previous study, we indicated that DP-LDL complex can selectively deliver DP into the aortic intima in a mouse model of atherosclerosis and the inhibitory effect of the DP-LDL complex on the development of atherosclerotic plaques was 100 times more potent than that of dexamethasone alone. ${ }^{12)}$ Therefore, KV-LDL complex may be delivered to the early atherosclerotic lesions in the aorta in atherogenic mice by intravenous injection, after which the KV-2920 released from the complex inhibits the development of atherosclerotic plaques.

In conclusion, the KV-LDL complex inhibits the foam cell formation of macrophages induced by incubation with both native LDL and oxidized LDL. The complex significantly inhibits CE accumulation in the aorta of atherogenic mice following intravenous injection, although its injection had no effect on serum cholesterol. These findings indicate that the KV-LDL complex is a useful formulation to prevent the development of atherosclerotic plaques in the aorta due to its high lipophilicity. Although there is a need for more information, we believe that the KV-LDL complex will be of benefit as a new formulation for antiatherosclerotic therapy in clinical situations.

Acknowledgements The authors acknowledge Prof. M. Kunitomo and Dr. Y. Yamaguchi of the Faculty of Pharmaceutical Science, Mukogawa Women's University for their technical advice in setting up the mouse model of atherosclerosis. They also wish to thank Dr. S. Chono for his technical assistance.

\section{REFERENCES}

1) Ross R., Nature (London), 362, 801-808 (1993).

2) Witztum J. L., Steinberg D., J. Clin. Invest., 88, 1785-1792 (1991).

3) Ryu B. H., Mao F. W., Lou P., Biosci. Biotech. Biochem., 59, 1619 1622 (1995)

4) Miyazaki A., Sakashita N., Lee O., Takahashi K., Horiuchi S., Hakamata H., Morganelli P. M., Chang C. C. Y., Chang T. Y., Arterioscler. Thromb. Vasc. Biol., 18, 1568-1574 (1998).

5) Rodriguez A., Bachorik P. S., Wee S. B., Arterioscler. Thromb. Vasc. Biol., 19, 2199-2206 (1999).

6) Asami Y., Yamaguchi I., Murakami S., Araki H., Tsuchida K., Higuchi S., Life Sci., 62, 1055-1063 (1998).

7) Chiwata T., Aragane K., Fujinami K., Kojima K., Ishibashi S., Yamada N., Kusunoki J., Br. J. Pharmacol., 133, 1005-1012 (2001).

8) Dominick M. A., McGuire E. J., Reindel J. F., Bobrowski W. F., Bocan T. M., Gough A. W., Fundam. Appl. Toxicol., 20, 217-224 (1993).

9) Matsuo M., Hashimoto M., Suzuki J., Iwanami K., Tomoi M., Shimomura K., Toxicol. Appl. Pharmacol., 140, 387-392 (1996).

10) Tauchi Y., Takase M., Zushida I., Chono S., Sato J., Ito K., Morimoto K., J. Pharm. Sci., 88, 709-714 (1999).

11) Tauchi Y., Zushida I., Yokota M., Chono S., Sato J., Ito K., Morimoto K., Biol. Pharm. Bull., 23, 466-471 (2000).

12) Tauchi Y., Zushida I., Chono S., Sato J., Ito K., Morimoto K., Biol. Pharm. Bull., 24, 925-929 (2001).

13) Kamiya S., Shirahase H., Yoshimi A., Nakamura S., Kanda M., Matsui 
H., Kasai M., Takahashi K., Kurahashi K., Chem. Pharm. Bull., 48, $817-827$ (2000).

14) Florence A. T., Halbert G. W., "Lipoprotein as Carriers of Pharmacological Agents," ed. by Shaw J. M., Sterling Drug Inc. Pennsylvania, 1991.

15) Hatch F., Less R. S., Adv. Lipid Res., 6, 2 -63 (1968).

16) Yamaguchi Y., Kitagawa S., Imaizumi N., Kunitomo M., Fujiwara M., J. Pharmacol. Toxicol. Methods, 30, 169-175 (1993).

17) Brandford M. M., Anal. Biochem., 72, 248-254 (1976).
18) Ishi I., Yokoyama M., Yanagimachi M., Ashikawa N., Hata M., Murakami S., Asami Y., Morisaki N., Saito Y., Ohmori S., Kitada M., J. Pharmacol. Exp. Ther., 287, 115-121 (1998).

19) Illingworth D. R., J. Nutr. Sci. Vitaminol., 39, $43-47$ (1993).

20) Rosen J. M., Butler S. P., Meinken G. E., Wang T. S. T., Ramakrishnan R., Srivastava S. C., Alderson P. O., Ginsberg H. N., J. Nucl. Med., 31, 343-350 (1990).

21) Xiao W., Wang L., Scott T., Counsell R. E., Liu H., Pharm. Res., 16, $420-426$ (1999). 